\title{
Augmentation of the antimicrobial activities of guinea pig cathelicidin CAP11-derived peptides by amino acid substitutions
}

\author{
DAIJU OKUDA $^{1}$, SHIN YOMOGIDA ${ }^{1}$, KYOKO KUWAHARA-ARAI ${ }^{2}$, \\ KEIICHI HITAMATSU ${ }^{2}$, HIROSHI TAMURA ${ }^{3}$ and ISAO NAGAOKA ${ }^{1}$

\begin{abstract}
Departments of ${ }^{1}$ Host Defense and Biochemical Research; ${ }^{2}$ Bacteriology, Juntendo University School of Medicine, 2-1-1 Hongo, Bunkyo-ku, Tokyo 113-8421; ${ }^{3}$ Seikagaku Biobusiness Corporation, 39 Kanda Higashimatsushita-cho, Chiyoda-ku, Tokyo 101-0042, Japan
\end{abstract}

Received November 19, 2008; Accepted January 15, 2009

DOI: 10.3892/ijmm_00000157

\begin{abstract}
Mammalian myeloid and epithelial cells express various peptide antibiotics (such as defensin and cathelicidin) that contribute to the innate host defense against invading microorganisms. Among these, guinea pig cathelicidin CAP11 $\left(\mathrm{G}^{1}-\mathrm{I}^{43}\right)$ possesses potent antibacterial activities against Gram-positive and -negative bacteria, and also lipopolysaccharide-neutralizing activity. We previously revealed that the active region with antibacterial activity is localized at $\mathrm{G}^{1}$ to $\mathrm{R}^{18}$ of CAP11. In this study, to develop peptide derivatives with enhanced antimicrobial actions, we utilized the amphipathic 18 -mer peptide $\left(\mathrm{G}^{1}-\mathrm{R}^{18}\right)$ as a template. Antimicrobial activities of the peptides were assessed by alamarBlue assay (Escherichia coli, Staphylococcus aureus and Candida albicans) and colony formation assay (Porphyromonas gingivalis). Furthermore, the membrane-permeabilization activities were determined by using $E$. coli ML-35p as a target. By substituting $\mathrm{K}^{5}, \mathrm{~T}^{9}, \mathrm{R}^{10}, \mathrm{R}^{12}$, and $\mathrm{G}^{17}$ with five $\mathrm{L}$ residues, the hydrophobicity of the peptide (1-18m1) was increased, and by substituting $\mathrm{G}^{1}$, and $\mathrm{Q}^{14}$ with $\mathrm{K}$ and $\mathrm{R}$ residues, respectively, the hydrophilicity (positive charge) of the peptide (1-18m2) was enhanced. Among the peptides, 1-18m2 exhibits the most potent antimicrobial and membranepermeabilizing activities against the microorganisms examined. Thus, the antimicrobial activities of the amphipathic CAP11derived 18-mer peptide can be augmented by modifying its hydrophobicity and hydrophilicity (positive charge), and 1$18 \mathrm{~m} 2$ is the most potent among the peptide derivatives with therapeutic potential for Gram-positive and -negative bacterial, and fungal infections.
\end{abstract}

Correspondence to: Dr Isao Nagaoka, Department of Host Defense and Biochemical Research, Juntendo University School of Medicine, 2-1-1 Hongo, Bunkyo-ku, Tokyo 113-8421, Japan

E-mail: nagaokai@juntendo.ac.jp

Key words: guinea pig, cathelicidin, antimicrobial host defense peptide

\section{Introduction}

Peptide antibiotics exhibit potent antimicrobial activities against both Gram-positive and -negative bacteria, fungi and viruses, and they form one group of effector components in the innate host defense system $(1,2)$. The peptide-based defense in mammals against invading microbes relies on the two evolutionally distinct groups of antimicrobial peptides, defensins and cathelicidins, which were identified in several epithelial tissues and in the granules of phagocytes (3-9). Defensins contain conserved six cysteine residues in their sequences and exhibit characteristic $\beta$-sheet structures stabilized by three intramolecular disulfide bonds (6-8). In contrast, cathelicidins are characterized by the highly conserved cathelin-like prosequences and variable carboxyl-terminal sequences that correspond to the mature antibacterial peptides $(3-5,9)$. About 30 cathelicidin members were identified in various mammalian species. Some are $\alpha$-helical, and others are proline/argininerich, showing a polyproline-type structure (e.g., porcine PR39 and bactenecins), whereas porcine protegrins form a $\beta$-sheet structure $(3,9,10)$. We have characterized two $\alpha$-helical cathelicidins, CAP18 (cationic antibacterial protein of $18 \mathrm{kDa}$ ) and CAP11 (cationic antibacterial polypeptides of $11 \mathrm{kDa}$ ) isolated from human and guinea pig neutrophils, respectively (11-13). CAP18 is a precursor of cathelicidin and its carboxyterminal antibacterial peptide (hCAP18/LL-37) is cleaved from its precursor $(3,9,10,14)$. CAP11 is also a carboxy-terminal antibacterial peptide, and has a unique homodimeric structure, in which the two identical 43-amino acid peptides are bridged by a disulfide bond $(12,13)$.

Among antibacterial peptides, defensins completely lose their antibacterial activities in the extracellular milieu containing a physiological concentration of $\mathrm{NaCl}(150 \mathrm{mM})$ and serum $(6,15)$. In contrast, cathelicidins, such as hCAP18/LL-37 and CAP11, exhibit antibacterial activities against Gram-negative and -positive bacteria under these conditions $(15,16)$. Furthermore, CAP11 exhibits 10-fold more potent antibacterial activities against Escherichia coli and Staphylococcus aureus than LL-37 (15). Thus, CAP11 and its related derivatives are attractive candidates for therapeutic agents for bacterial infections $(11,15-18)$. 
A

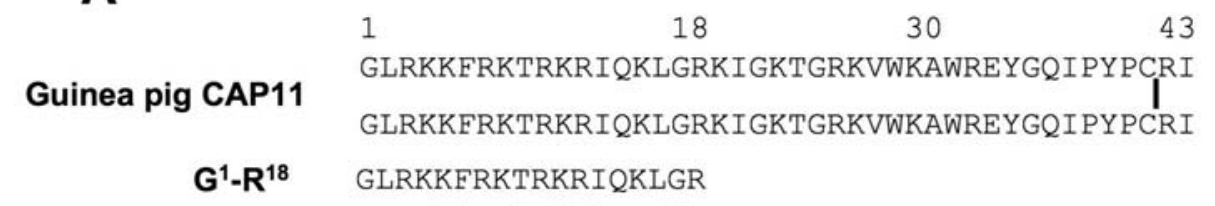

1-18m1 GLRKEFRKELKETQKLER

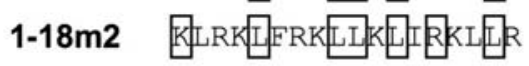
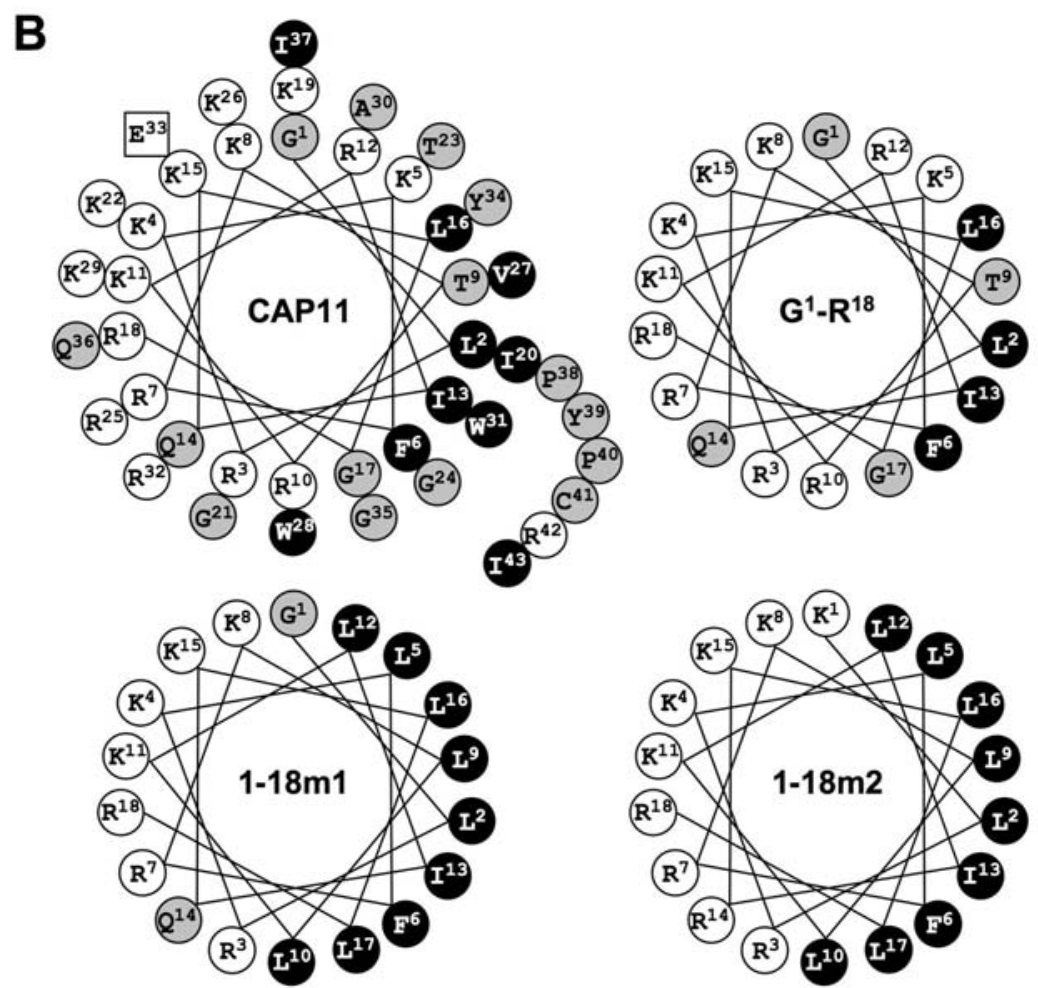

Figure 1. Amino acid sequences and helical-wheel projections of CAP11-related peptides. (A) Native CAP11 forms a homodimeric structure with a disulfide bridge at the $\mathrm{C}^{41}$ residue. Boxes in the $1-18 \mathrm{~m} 1$ and 2 sequences indicate the substituted amino acid residues introduced into the original $\mathrm{G}^{1}-\mathrm{R}^{18}$ to increase the hydrophobicity and hydrophilicity (positive charge) of the peptides. (B) The sequences of CAP11-derived $\alpha$-helical peptides, $\mathrm{CAP} 11\left(\mathrm{G}^{1}-\mathrm{I}^{43}\right), \mathrm{G}^{1}-\mathrm{R}^{18}, 1-18 \mathrm{~m} 1$, and 2 are presented according to the Shiffer-Edmundson wheel projection analysis. Positively charged residues are in white circles, hydrophobic residues are in black circles, neutral hydrophilic residues are in gray circles, and negatively charged residues are in boxes.

Although antibacterial peptides are diverse in size, structure and activity, they are mostly amphipathic, retaining both cationic (positively charged) and hydrophobic faces $(2,3,17,19)$. These features facilitate their interactions with the negatively charged microbial surface membranes, followed by insertion into the microbial lipid membrane, thereby altering membrane permeability and impairing internal homeostasis $(2,3,17,19)$. Secondary structure predictions indicate that some cathelicidin members (such as hCAP18/LL-37, rabbit CAP18derived peptide and guinea pig CAP11) adopt an $\alpha$-helical amphipathic conformation $(3,12-14,16)$; the helical wheel regions are clearly amphipathic and subtended by the hydrophilic (positively charged) and hydrophobic sectors (CAP11 is shown in Fig. 1). Notably, structure-activity relationship (SAR) studies using different kinds of natural and synthetic model peptides revealed that the potency and spectrum of the amphipathic $\alpha$-helical antimicrobial peptides is influenced by the interrelated structural and physicochemical parameters such as charge (cationicity), hydrophobicity and amphipathicity $(20,21)$. Thus, by changing these parameters one could design novel antimicrobial peptides with increased potency and directed activity.

During analysis of the antibacterial regions of guinea pig CAP11, we previously found that the active region with antibacterial activity is localized at $\mathrm{G}^{1}$ to $\mathrm{R}^{18}$ (22). Thus, the 18 -mer peptide of CAP11 $\left(\mathrm{G}^{1}-\mathrm{R}^{18}\right)$ is a good template for development of therapeutic agents that can be used for treatment or prevention of bacterial infections. In this study, to develop the antimicrobial peptides with enhanced activities, we modified the hydrophobicity and hydrophilicity (positive charge) of the peptide by substituting with leucine and lysine/arginine residues, respectively, and evaluated the activities of those peptide derivatives by using E. coli, S. aureus (methicillinsensitive and -resistant), Porphyromonas gingivalis and Candida albicans as target organisms.

\section{Materials and methods}

Reagents. Mueller Hinton broth was purchased from Difco Laboratories (Detroit, MI), heart infusion broth from Nissui 
Pharmaceutical Co., Ltd. (Tokyo, Japan), Sabouraud dextrose agar from Becton Dickinson and Company (Sparks, MD), Brucella HK agar from Kyokuto Pharmaceutical Industrial Co., Ltd. (Tokyo, Japan), defibrinized sheep blood was purchased from Japan Ram Co., Ltd. (Hiroshima, Japan), hemin chloride from MP Biomedicals (Aurora, OH), PADAC (7-(thienyl-2-acetamido)-3-[2-(4-N,N-dimetyl-amino phenylazo)-pyridinium methyl]-3-cephem-4-carboxylic acid) from Calbiochem-Novabiochem (La Jolla, CA), o-nitrophenylß-D-galactopyranoside (ONPG) from Sigma Chemical Co. (St. Louis, MO), alamarBlue was purchased from Biosource International, Inc. (Camarillo, CA).

Synthesis and isolation of CAP11-derived peptides. A 43-mer peptide of CAP11 (G $\mathrm{G}^{1} \mathrm{I}^{43}$; G $\mathrm{G}^{1}$ LRKKFRKTRKRIQKLGRKIG KTGRKVWKAWREYGQIPYPCRI $\left.{ }^{43}\right)$ and CAP11-derived 18mer peptides $\left(\mathrm{G}^{1}-\mathrm{R}^{18}, \mathrm{G}^{1}\right.$ LRKKFRKTRKRIQKLGR ${ }^{18} ; 1-18 \mathrm{~m} 1$, $\mathrm{G}^{1}$ LRKLFRKLLKLIQKLLLR ${ }^{18}$ and $1-18 \mathrm{~m} 2, \underline{\mathrm{K}}^{1} \mathrm{LRKLFRKLLK}$ LIRKLL $\underline{R}^{18}$ ) were synthesized by the solid-phase method on a peptide synthesizer (model PSSM-8, Shimadzu, Kyoto, Japan) by fluorenylmethoxycarbonyl (Fmoc) chemistry [underlines indicate the amino acid substitutions introduced into the original 18 -mer peptide $\mathrm{G}^{1}-\mathrm{R}^{18}$ to increase the hydrophobicity and hydrophilicity (positive charge) of the peptides]. The peptides were eluted from the resin and purified to homogeneity by reversed-phase high-performance liquid chromatography on a Cosmosil 5C18 column (Nacalai Tesque, Kyoto, Japan) using a 0 to $70 \%$ acetonitrile gradient in $0.1 \%$ trifluoroacetic acid. The molecular masses of the synthesized peptides were confirmed on a mass spectrometer (model TSQ 700; Thermo Quest Finnigan, Manchester, UK). $\mathrm{G}^{1}-\mathrm{I}^{43}$ peptides were always freshly dissolved in $0.01 \% \mathrm{HCl}$ and used, to avoid auto-dimerization.

Assay for the antimicrobial activities. To determine the antimicrobial activities of peptides, alamarBlue was used as a metabolic indicator. As a consequence of bacterial growth, the color of an oxidation-reduction indicator alamarBlue changes from blue to pink. It was confirmed that the classical colony formation and the alamarBlue assay using a redox indicator are comparable to evaluate the bacterial viability; the results of two methods significantly correlate, and the bacterial concentrations determined by the two assays show agreement (23-25). In fact, we previously confirmed that CAP11 completely killed E. coli at $189 \mathrm{nM}(1 \mu \mathrm{g} / \mathrm{ml})$ but hardly affected the bacterial growth at $18.9 \mathrm{nM}(0.1 \mu \mathrm{g} / \mathrm{ml})$, based on the classical colony formation and alamarBlue assay (22). Thus, we evaluate the antibacterial activities of CAP11 and its derived-peptide by using alamarBlue as a metabolic indicator.

As target organisms, E. coli, S. aureus and C. albicans were utilized. E. coli (NIHJ JC-2), methicillin-sensitive $S$. aureus (MSSA) (NIHJ JC-1) and methicillin-resistant $S$. aureus (MRSA) (LR5P1-IPM8-1, a highly resistant isolate derived from N315) were supplied by Professor Keiichi Hiramatsu (Department of Bacteriology, Juntendo University, School of Medicine); C. albicans (CA53133) by Professor Masataro Hiruma (Department of Dermatology, Juntendo University, School of Medicine). E. coli and S. aureus were cultured in Mueller Hinton broth at $37^{\circ} \mathrm{C}$ for $14 \mathrm{~h}$ with shaking. Cells were centrifuged, washed twice with RPMI-1640 medium without phenol red and diluted in the same medium. Bacteria were incubated in the dark at $37^{\circ} \mathrm{C}$ for 4 to $6 \mathrm{~h}$ at indicated concentrations ( $1 \times 10^{7} \mathrm{CFU} / \mathrm{ml}$, E. coli $; 5 \times 10^{6} \mathrm{CFU} / \mathrm{ml}$, S. aureus) in RPMI-1640 medium containing $20 \mu \mathrm{l}$ alamarBlue in the absence or presence of antibacterial peptides dissolved in $0.01 \% \mathrm{HCl}$ in a total volume of $200 \mu 1$ in a 96-well microplate. C. albicans was cultured on Sabouraud dextrose agar plates at $35^{\circ} \mathrm{C}$ for $14 \mathrm{~h}$, and then the colonies were suspended in RPMI-1640-medium at $2.5 \times 10^{6} \mathrm{CFU} / \mathrm{ml}$. The cells $(C$. albicans) were incubated in the presence of alamarBlue without or with antimicrobial peptides at $35^{\circ} \mathrm{C}$ for $14 \mathrm{~h}$ in a total volume of $200 \mu \mathrm{l}$. Aliquots containing all assay reagents except cells were used as blanks. After incubation, the absorbance at 550 and $590 \mathrm{~nm}$ was measured using a microplate reader (Model680 Bio-Rad Laboratories, Inc., Hercules, CA) and expressed as bacterial growth. $\mathrm{EC}_{50}$ values of antimicrobial activities were determined as the concentrations of peptides that were required for $50 \%$ inhibition of the maximum microbial growth (absorbance at 550 and 590 $\mathrm{nm}$ ) observed in the absence of antimicrobial peptides. In preliminary experiments, a standard curve of each bacterial clone was obtained by performing alamarBlue assay with serially diluted bacterial suspensions, and the optimal concentrations of each bacterial species, described above, were determined for the quantifications.

Antibacterial activities against $P$. gingivalis were determined by a colony formation assay under anaerobic conditions. In brief, $P$. gingivalis, supplied by Dr Tomoko Ohshima and Professor Nobuko Maeda (Department of Oral Bacteriology, Tsurumi University, School of Dental Medicine), was cultured in Brain Heart Infusion (BHI) broth containing hemin chloride $(5 \mu \mathrm{g} / \mathrm{ml})$ and vitamin $\mathrm{K}_{2}(1 \mu \mathrm{g} / \mathrm{ml})$ with shaking under anaerobic condition, at $37^{\circ} \mathrm{C}$ for 3 to 4 days. Then, the cells were centrifuged, suspended at $5 \times 10^{3} \mathrm{CFU} / \mathrm{ml}$ in BHI broth, and incubated without or with antimicrobial peptides at $37^{\circ} \mathrm{C}$ for $30 \mathrm{~min}$. Thereafter, the cells ( $\sim 500 \mathrm{CFU})$ were spread on blood agar plates and incubated under anaerobic conditions at $37^{\circ} \mathrm{C}$ for 6 days to allow full colony development. Antimicrobial activities of the peptides were evaluated by counting the colonies formed.

Membrane permeabilization assay. To examine the ability of antimicrobial peptides to permeabilize the outer and inner membranes of bacteria, we used $E$. coli ML-35p as a target organism $(3,15,26,27)$. E. coli ML-35p was constructed by transforming E. coli ML-35 (i-, y-, z+) with pBR322 to constitutively express plasmid encoded periplasmic $\beta$-lactamase. Because ML-35p is constitutive for cytoplasmic B-galactosidase but lactose permease-deficient like its parent strain E. coli ML-35, intact E. coli ML-35p cells cannot hydrolyze $\beta$-galactosidase substrate until their cytoplasmic membranes are permeabilized by antibacterial peptides. After cells were cultured in tryptic soy broth containing $50 \mu \mathrm{g} / \mathrm{ml}$ ampicillin at $37^{\circ} \mathrm{C}$ for $14 \mathrm{~h}$, cells were washed three times with $10 \mathrm{mM}$ phosphate buffer ( $\mathrm{pH} 7.4)$ containing $150 \mathrm{mM}$ $\mathrm{NaCl}$, and diluted in the same buffer to $1 \times 10^{8} \mathrm{CFU} / \mathrm{ml}$. Outer and inner membrane permeabilization of $E$. coli ML-35p was evaluated by following the unmasked periplasmic B-lactamase and cytoplasmic $\beta$-galactosidase activities using PADAC, a 


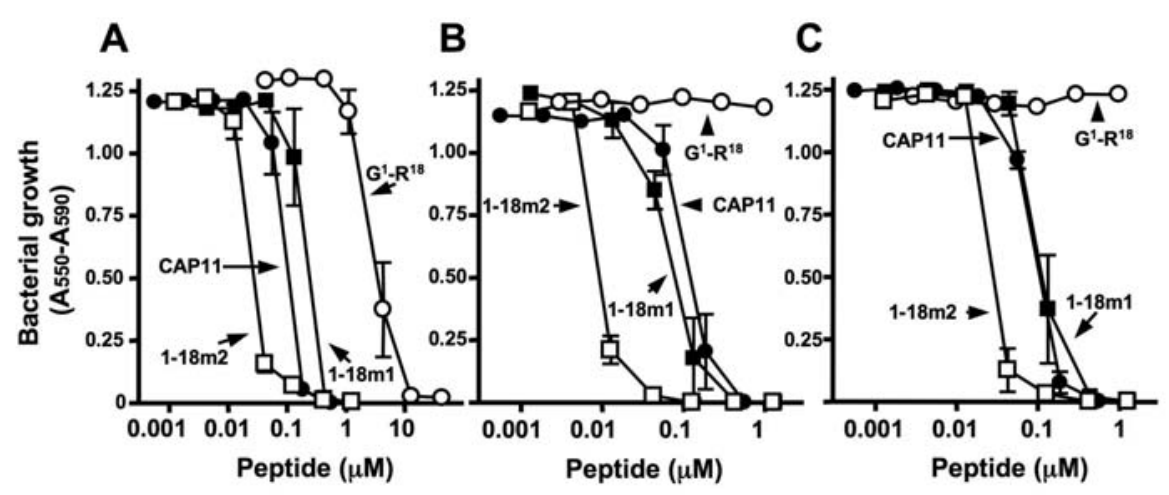

Figure 2. Antimicrobial activities of CAP11-related peptides against E. coli and S. aureus. Antibacterial activities of CAP11-related peptides (CAP11, G ${ }^{1} \mathrm{R}^{18}$, 1-18m1 and 2) were assayed with the alamarBlue assay using E. coli (A), methicillin-sensitive S. aureus (MSSA) (B), and methicillin-resistant S. aureus (MRSA) (C) as targets. Data are the mean $\pm \mathrm{SD}$ of four independent experiments.

chromogenic cephalosporin, and ONPG as substrates, respectively. The assay was performed at $37^{\circ} \mathrm{C}$ with shaking in a 96-well microplate containing $10^{7} \mathrm{CFU} / \mathrm{ml}$ of $E$. coli ML-35p, $200 \mu \mathrm{M}$ PADAC or $1 \mathrm{mM}$ ONPG in atal volume of $200 \mu 110 \mathrm{mM}$ phosphate buffer (pH 7.4) containing $150 \mathrm{mM}$ $\mathrm{NaCl}$. The reactions were started by addition of antibacterial peptides or $0.01 \% \mathrm{HCl}$ (a solvent of antibacterial peptides), and monitored for $30 \mathrm{~min}$ at 570 or $405 \mathrm{~nm}$ with a microplate reader (Model BenchmarkPlus, Bio-Rad Laboratories). Membrane permeabilization was determined by calculating the changes in the absorbance at linear portion and expressed as a percent of the enzyme activity determined with bacteria completely permeabilized by sonication.

Helical wheel prediction. The $\alpha$-helical wheel structures of CAP11-derived peptides were predicted by using a GenetyxWin computer system (Genetyx, Tokyo, Japan) and a Java applet on WWW (http://cti.itc.virginia.edu/ cmg/Demo/wheel/ wheelApp.html).

Hydropathy indices calculated by the algorithm of Hopp and Woods, and $\mathrm{pI}$ values of CAP11 and its derivatives $\left(\mathrm{G}^{1}-\mathrm{R}^{18}\right.$, $1-18 \mathrm{~m} 1$ and 2 ) were also determined by the same system.

\section{Results}

Antibacterial activities of 18-mer peptides against E. coli and $S$. aureus. We first examined the antibacterial activities of $\mathrm{G}^{1}-\mathrm{R}^{18}$-derived 18 -mer peptides using E. coli and MSSA as target organisms. The 18-mer peptides, as well as CAP11, dose-dependently inhibited the growth of both E. coli and MSSA (Fig. 2A and B). Interestingly, 1-18m2 was the most potent among the peptide derivatives at suppressing the growth of these bacteria. $\mathrm{ED}_{50}$ values against $E$. coli and MSSA were 0.023 and $0.008 \mu \mathrm{M}$ for $1-18 \mathrm{~m} 2,0.085$ and $0.063 \mu \mathrm{M}$ for $1-18 \mathrm{~m} 1,2.91$ and $>1 \mu \mathrm{M}$ for $\mathrm{G}^{1}-\mathrm{R}^{18}$, and 0.202 and $0.107 \mu \mathrm{M}$ for CAP11, respectively.

We next accessed the antibacterial activities of $\mathrm{G}^{1}-\mathrm{R}^{18}$. derived 18-mer peptides using MRSA as a target organism. Similar to the actions on MSSA, the peptide derivatives suppressed the growth of MRAS in a dose-dependent manner, and $1-18 \mathrm{~m} 2$ was the most potent among the CAP11-derived peptides (Fig. 2C). $\mathrm{ED}_{50}$ values against MRSA were $0.024 \mu \mathrm{M}$ for $1-18 \mathrm{~m} 2,0.096 \mu \mathrm{M}$ for $1-18 \mathrm{~m} 1$ and CAP11, $>1 \mu \mathrm{M}$ for $\mathrm{G}^{1}-\mathrm{R}^{18}$.
Antibacterial activities of 18-mer peptides against $P$. gingivalis and $C$. albicans. Further, we evaluated the antimicrobial actions of CAP11-derived peptides using $P$. gingivalis and $C$. albicans as target organisms. Similar to the actions on aerobic bacteria (E. coli and S. aureus), CAP11-derived peptides dosedependently inhibited the growth of an anaerobic bacterium ( $P$. gingivalis) and a fungus (C. albicans), and $1-18 \mathrm{~m} 2$ was the most potent among the peptide derivatives (Fig. 3A and B). $\mathrm{ED}_{50}$ values against $P$. gingivalis were $0.195 \mu \mathrm{M}$ for $1-18 \mathrm{~m} 2$, $1.28 \mu \mathrm{M}$ for $1-18 \mathrm{~m} 1,>10 \mu \mathrm{M}$ for $\mathrm{G}^{1}-\mathrm{R}^{18}$, and $6.1 \mu \mathrm{M}$ for CAP11. $\mathrm{ED}_{50}$ values against $C$. albicans were $0.72 \mu \mathrm{M}$ for $1-18 \mathrm{~m} 2,1.30 \mu \mathrm{M}$ for $1-18 \mathrm{~m} 1,>10 \mu \mathrm{M}$ for $\mathrm{G}^{1}-\mathrm{R}^{18}$, and $1.92 \mu \mathrm{M}$ for CAP11.

Membrane-permeabilization activities of 18-mer peptides against E. coli $M L-35 p$. Finally, to elucidate the mechanism for the antimicrobial actions of CAP11-derived peptides, we assessed their membrane-permeabilization activities using E. coli ML-35p as a target organism. Outer and inner membrane permeabilization is determined by quantifying the unmasked periplasmic $\beta$-lactamase and cytoplasmic $\beta$-galactosidase activities of $E$. coli ML-35p, respectively. The peptide derivatives dose-dependently induced the outer and inner membrane permeabilization. Consistent with the results of antimicrobial activities, $1-18 \mathrm{~m} 2$ was the most potent among the CAP11-derived peptides at inducing the inner membrane permeabilization $\left(\mathrm{ED}_{50}\right.$ values, $0.16 \mu \mathrm{M}$ for $1-18 \mathrm{~m} 2,0.51 \mu \mathrm{M}$ for $1-18 \mathrm{~m} 1$ and $>10 \mu \mathrm{M}$ for $\mathrm{G}^{1}-\mathrm{R}^{18}$ and CAP11) (Fig. 4A). In contrast, the outer membrane permeabilizing activities of 1$18 \mathrm{~m} 2,1$ and CAP11 were almost the same $\left(\mathrm{ED}_{50}\right.$ values, 1.10 to $5.03 \mu \mathrm{M})$ (Fig. 4B).

\section{Discussion}

For prevention of bacterial infection and their related symptoms (e.g. Gram-negative bacterial septic shock), much attention is focused on the low-molecular-weight cationic antibacterial peptides that possess potent antimicrobial activity. CAP11 has a unique homodimeric structure of 43-amino-acid peptides with a disulfide bridge $(12,13)$. In a previous study, we revealed that the peptide dimerization is not necessary for the biological activities of CAP11. Moreover, we determined the biologically active region of CAP11, which is located at the 
A

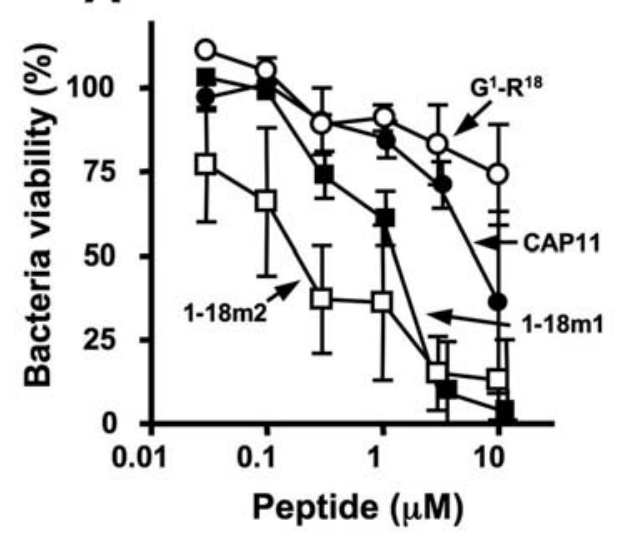

B

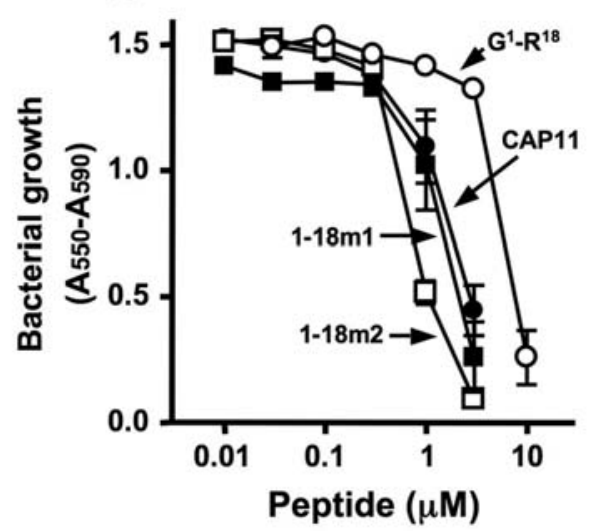

Figure 3. Antimicrobial activities of CAP11-related peptides against P. gingivalis and C. albicans. Antimicrobial activities of CAP11-related peptides (CAP11, $\mathrm{G}^{1}-\mathrm{R}^{18}, 1-18 \mathrm{~m} 1$ and 2 ) were assayed with the colony formation and alamarBlue assays using $P$. gingivalis (A) and $C$. albicans (B), respectively, as targets. Data are the mean $\pm \mathrm{SD}$ of three to four independent experiments.
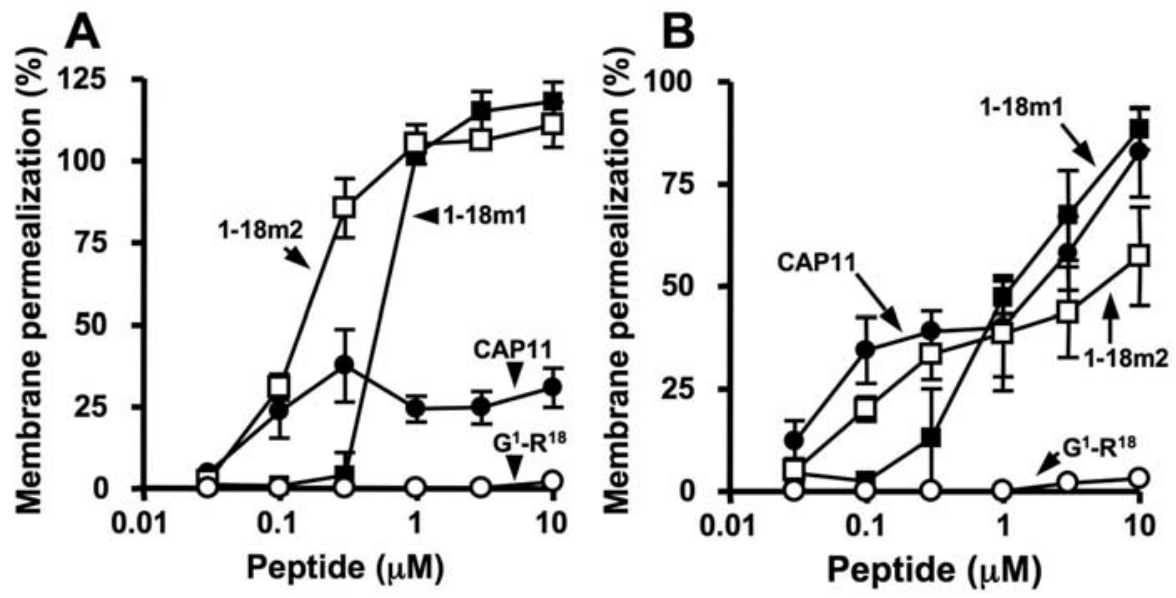

Figure 4. Bacterial membrane-permeabilization activities of CAP11-related peptides. E. coli ML-35p was incubated in the absence or presence of CAP11related peptides (CAP11, G ${ }^{1}-\mathrm{R}^{18}, 1-18 \mathrm{~m} 1$ and 2 ) with an enzyme substrate (PADAC and ONPG) for measuring periplasmic B-lactamase and cytoplasmic B-galactosidase activities, respectively. Inner (A) and outer (B) membrane permeabilization is expressed as a percent of the enzyme activity determined with bacteria completely permeabilized by sonication. Data are the mean $\pm \mathrm{SD}$ of four independent experiments.

N-terminus $\left(\mathrm{G}^{1}-\mathrm{R}^{18}\right)$ of CAP11. However, the biological activities of the short peptide $\left(\mathrm{G}^{1}-\mathrm{R}^{18}\right)$ were much lower than those of a full-length CAP11. Thus, in the present study, we aimed to develop the antimicrobial peptide(s) with enhanced biological activities by amino acid substitutions, using $\mathrm{G}^{1}-\mathrm{R}^{18}$ as a template. Some antimicrobial peptides conform to an amphipathic $\alpha$-helix structure with the hydrophobic and hydrophilic (positively charged) surfaces $(5,30)$. Of note, structureactivity relationship (SAR) studies using different kinds of natural and synthetic model peptides revealed that the activities of amphipathic $\alpha$-helical antimicrobial peptides is influenced by parameters such as charge (cationicity), hydrophobicity and amphipathicity, and that the maximum antibacterial potency is obtained when high charge (cationicity) and amphipathicity are achieved $(20,21)$. Based on these observations, we constructed the two modified peptides, 1-18m1 and 2, with the increased hydrophobicity and hydrophilicity (positive charge) (Figs. 1 and 5).

We evaluated the antibacterial activities of the peptides against Gram-negative and -positive bacteria. The antibacterial activities of the two peptides (1-18m1 and 2) against $E$. coli and $S$. aureus (MSSA) were markedly increased compared with those of $\mathrm{G}^{1}-\mathrm{R}^{18} ; 1-18 \mathrm{~m} 1$ has almost the same activity as CAP11, and 1-18m2 exhibited the most potent activities, which were $\sim 10$-fold stronger than those of CAP11. Of note, CAP11 and its modified peptides (1-18m1 and 2) also possessed the potent antibacterial activities against MRSA. These results suggest that CAP11-derived peptides (CAP11, 1-18m1 and 2) exhibit the antibacterial activities against $S$. aureus despite the methicillin-resistance.

Further, we evaluated the antimicrobial activities of CAP11-derived peptides against $P$. gingivalis, an anaerobic bacterium, and $C$. albicans, a fungus. CAP11 and its related peptides exhibited potent antimicrobial activities against these microorganisms, and $1-18 \mathrm{~m} 2$ was the most potent. However, these microbes were relatively resistant to the CAP11-derived peptides; $\mathrm{EC}_{50}$ values $(>0.195 \mu \mathrm{M})$ against $P$. gingivalis and $C$. albicans were 20 -fold higher than those $(>0.008 \mu \mathrm{M})$ against $E$. coli and $S$. aureus. In concordance with our findings, previous studies revealed that $P$. gingivalis 


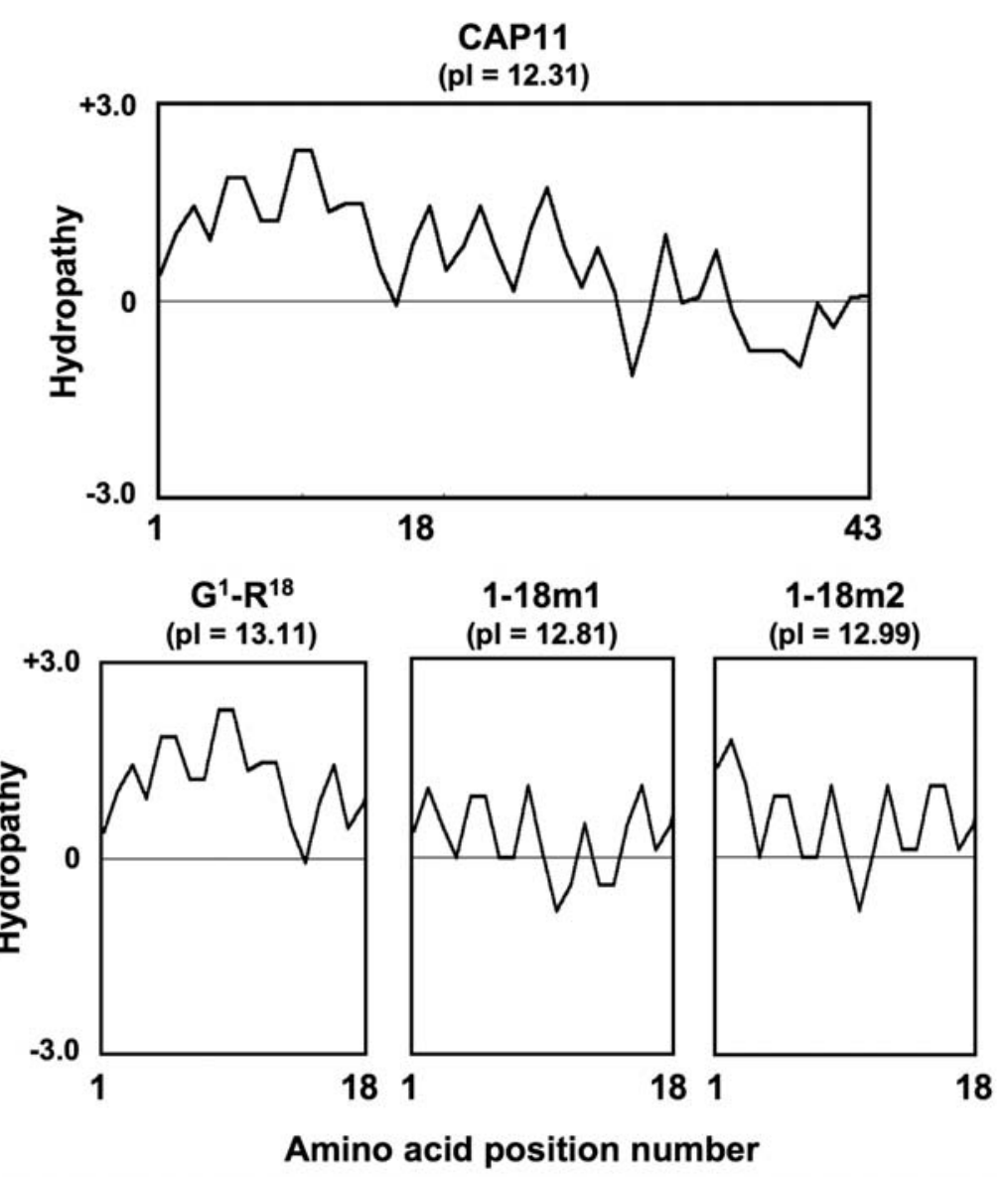

Figure 5. Hydrophilicity/hydrophobicity plots of CAP11-related peptides. Hydropathy indices (+, hydrophilicity; -, hydrophobicity) of CAP11 and its related peptides $\left(\mathrm{G}^{1}-\mathrm{R}^{18}, 1-18 \mathrm{~m} 1\right.$, and 2$)$ were calculated by the algorithm of Hopp and Woods by using a Genetyx-Win computer system, and the pI values of the peptides were also determined by the same system. Horizontal axes display the amino acid position number.

and $C$. albicans were resistant to antimicrobial peptides such as LL-37 and B-defensin 3; MIC values (>22 $\mu \mathrm{M})$ against $P$. gingivalis and $C$. albicans were much higher than those $(>1.2 \mu \mathrm{M})$ against $E$. coli and $S$. aureus based on a radial diffusion assay $(15,28,29)$. $P$. gingivalis forms a biofilm, which confers the resistance to antimicrobial agents (30). Furthermore, $P$. gingivalis produces the two families of cysteine-proteases, Arg- and Lys-gingipain, which digest various peptides at arginine or lysine residue, respectively (31-33). CAP11 and its related peptides contain several cationic amino acids (i.e., Arg and Lys) in their sequences. Thus, the gingipains are likely to degrade these cationic amino acidcontaining peptides during incubation, which confers the resistance on the microbe to antibacterial peptides. Bacterial membrane contains abundant negative-charged phospholipids such as phosphatidyl glycerol and cardiolipin $(21,34)$. Therefore, the cationic antibacterial peptides possess high affinities for bacterial membrane components and kill bacteria by permeabilization and/or disruption of their membrane $(17,21,34)$. In contrast, the mammalian cell membrane is mainly composed of uncharged phospholipids, such as phosphatidylcholine and sphingomyelin, resulting in a lower affinity of antibacterial peptides against mammalian cells. Moreover, the existence of membrane-stabilizing cholesterol protects mammalian host cells from the toxicity of antibacterial peptides. Comparable to eukaryotic cells, fungi, such as
C. albicans, have a bilayered membrane structure, which contains several sterols such as ergosterol and zymosterol. Thus, it is speculated that antimicrobial peptides have difficulty in contacting to and disrupting the fungal membrane, making $C$. albicans resistant to antimicrobial peptides.

To further elucidate the antimicrobial mechanism of CAP11-derived peptides, we investigated that membranepermeabilization activity using $E$. coli $\mathrm{ML}-35$ p by measuring -lactamase and -galactosidase activities. Except for $\mathrm{G}^{1}-\mathrm{R}^{18}$, the peptides disrupted the outer membrane in a dosedependent manner with the similar $\mathrm{EC}_{50}$ values (1.10 to $5.03 \mu \mathrm{M})$. In contrast, for the inner membrane-permeabilization, $1-18 \mathrm{~m} 2$ showed the most potent activity with the $\mathrm{EC}_{50}$ value of $0.16 \mu \mathrm{M}$. Unexpectedly, CAP11 only minimally possessed inner membrane-permeabilization activity $(\sim 30 \%)$ even at $>10 \mu \mathrm{M}$. These observations suggest that the potent antibacterial activities of $1-18 \mathrm{~m} 2$ likely depend on its preferential action on the inner membrane-permeabilization.

In this study, to develop CAP11-derived antimicrobial peptides with enhanced bactericidal activities, we utilized the 18-mer peptide $\left(\mathrm{G}^{1}-\mathrm{R}^{18}\right)$ of CAP11 as a template, and evaluated the activities of its peptide derivatives. By replacement of $\mathrm{K}^{5}$, $\mathrm{T}^{9}, \mathrm{R}^{10}, \mathrm{R}^{12}$ and $\mathrm{G}^{17}$ with five $\mathrm{L}$ residues, hydrophobicity of the peptide was increased and the hydrophobic sector in the helix was extended (Figs. 1 and $5 ; \mathrm{G}^{1}-\mathrm{R}^{18}$ vs. 1-18m1). Furthermore, by replacement of $\mathrm{G}^{1}$ and $\mathrm{Q}^{14}$ with $\mathrm{K}$ and $\mathrm{R}$ 
residues, respectively, hydrophilicity of the peptide was enhanced and the positively charged hydrophilic sector in the helix was expanded (1-18m1 vs. 1-18m2). Among these peptides, $1-18 \mathrm{~m} 2$ displayed the most potent antibacterial and membrane-permeabilizing activities. Thus, the enhanced hydrophobicity and hydrophilicity (positive charge) of 1-18m2 are important for the expression of its augmented antibacterial activities. These observations suggest that the $\alpha$-helical amphipathic anti-microbial peptides, with increased hydrophobicity and hydrophilicity (positive charge) (1-18m2), interact more potently with negatively charged amphipathic bacterial membrane, compared with the parent 18 -mer peptide, thereby exerting augmented bactericidal activities. In contrast, the deduced $\mathrm{pI}$ values of CAP11-derived peptides were not essentially changed after the amino acid substitutions; 13.11 for $\mathrm{G}^{1}-\mathrm{R}^{18}, 12.81$ for $1-18 \mathrm{~m} 1,12.99$ for $1-18 \mathrm{~m} 2$ and 12.31 for CAP11 (Fig. 5), suggesting that antibacterial activities of CAP11 and its related peptides could not be determined simply by the basic (cationic) features of the molecules.

Cationic antimicrobial peptides target cell-surface anionic lipids (phosphatidyl glycerol and cardiolipin) that are abundant in microorganisms; the action is not receptor-based but involves a less specific interaction with microbial membrane components $(21,34)$. The simple electrostatic interaction between cationic antimicrobial peptides and microbial membrane lipids provides selective toxicity (bacteria vs. mammalian cells) as well as a broad spectrum of antimicrobial activities. Moreover, development of microbial resistance is assumed to be low, because the target molecules (anionic lipids) are important components conserved among microorganisms, and the molecular recognition between cationic peptides and target molecules is rather lenient $(3,21,34)$. In addition, sizes of the peptides are small, and their syntheses are relatively accessible. From these points of view, cationic antimicrobial peptides are a promising candidate for new antibiotics with therapeutic value. Previously, we revealed that CAP11 possesses not only antimicrobial activity but also LPS-neutralizing activity. Preliminarily, we evaluated the LPS-neutralizing activities of $1-18 \mathrm{~m} 1$ and 2 , based on the suppression of LPS-binding to CD14-positive RAW264.7 cells, and of LPS-induced cytokine production from these cells. Notably, these modified peptides exhibited potent LPSneutralizing activities, and $1-18 \mathrm{~m} 2$ was $\sim 20$-fold more potent than CAP11 (unpublished data). These observations suggest that the modified CAP11-related peptides are one of the new classes of antibiotics that can be used for treatment of microbial infections and their related symptoms (Gramnegative bacterial sepsis) in the future.

\section{Acknowledgements}

This work was supported in part by grants from Glant-in-Aid for 21 st Century COE research and the Institute for Environmental and Gender-specific Medicine, Juntendo University School of Medicine.

\section{References}

1. Hancock RE and Diamond G: The role of cationic antimicrobial peptides in innate host defences. Trends Microbiol 8: 402-410, 2000.
2. Risso A: Leukocyte antimicrobial peptides: multifunctional effector molecules of innate immunity. J Leukoc Biol 68: 785-792, 2000.

3. Gennaro R and Zanetti M: Structural features and biological activities of the cathelicidin-derived antimicrobial peptides. Biopolymers 55: 31-49, 2000.

4. Gudmundsson GH and Agerberth B: Neutrophil antibacterial peptides, multifunctional effector molecules in the mammalian immune system. J Immunol Methods 232: 45-54, 1999.

5. Lehrer RI and Ganz T: Cathelicidins: a family of endogenous antimicrobial peptides. Curr Opin Hematol 9: 18-22, 2002.

6. Lehrer RI and Ganz T: Defensins of vertebrate animals. Curr Opin Immunol 14: 96-102, 2002.

7. Lehrer RI, Lichtenstein AK and Ganz T: Defensins: antimicrobial and cytotoxic peptides of mammalian cells. Annu Rev Immunol 11: $105-128,1993$.

8. Martin E, Ganz T and Lehrer RI: Defensins and other endogenous peptide antibiotics of vertebrates. J Leukoc Biol 58: 128-136, 1995.

9. Zanetti M, Gennaro R and Romeo D: Cathelicidins: a novel protein family with a common proregion and a variable $\mathrm{C}$-terminal antimicrobial domain. FEBS Lett 374: 1-5, 1995.

10. Hancock RE and Chapple DS: Peptide antibiotics. Antimicrob Agents Chemother 43: 1317-1323, 1999.

11. Kirikae T, Hirata M, Yamasu H, Kirikae F, Tamura H, Kayama F, Nakatsuka K, Yokochi T and Nakano M: Protective effects of a human 18-kilodalton cationic antimicrobial protein (CAP18)derived peptide against murine endotoxemia. Infect Immun 66: 1861-1868, 1998

12. Nagaoka I, Tsutsumi-Ishii Y, Yomogida S and Yamashita T: Isolation of cDNA encoding guinea pig neutrophil cationic antibacterial polypeptide of $11 \mathrm{kDa}$ (CAP11) and evaluation of CAP11 mRNA expression during neutrophil maturation. J Biol Chem 272: 22742-22750, 1997.

13. Yomogida S, Nagaoka I and Yamashita T: Purification of the 11- and 5-kDa antibacterial polypeptides from guinea pig neutrophils. Arch Biochem Biophys 328: 219-226, 1996.

14. Turner J, Cho Y, Dinh NN, Waring AJ and Lehrer RI: Activities of LL-37, a cathelin-associated antimicrobial peptide of human neutrophils. Antimicrob Agents Chemother 42: 2206-2214, 1998.

15. Nagaoka I, Hirota S, Yomogida S, Ohwada A and Hirata M: Synergistic actions of antibacterial neutrophil defensins and cathelicidins. Inflamm Res 49: 73-79, 2000.

16. Larrick JW, Hirata M, Zhong J and Wright SC: Anti-microbial activity of human CAP18 peptides. Immunotechnology 1: 65-72, 1995.

17. Levy O: Antimicrobial proteins and peptides of blood: templates for novel antimicrobial agents. Blood 96: 2664-2672, 2000.

18. Nagaoka I, Hirota S, Niyonsaba F, Hirata M, Adachi Y, Tamura H and Heumann D: Cathelicidin family of antibacterial peptides CAP18 and CAP11 inhibit the expression of TNF- $\alpha$ by blocking the binding of LPS to CD14+ cells. J Immunol 167: 3329-3338, 2001.

19. Hancock RE and Scott MG: The role of antimicrobial peptides in animal defenses. Proc Natl Acad Sci USA 97: 8856-8861, 2000.

20. Giangaspero A, Sandri L and Tossi A: Amphipathic alpha helical antimicrobial peptides. Eur J Biochem 268: 5589-5600, 2001.

21. Tossi A, Sandri L and Giangaspero A: Amphipathic, alphahelical antimicrobial peptides. Biopolymers 55: 4-30, 2000.

22. Okuda D, Yomogida S, Tamura H and Nagaoka I: Determination of the antibacterial and lipopolysaccharide-neutralizing regions of guinea pig neutrophil cathelicidin peptide CAP11. Antimicrob Agents Chemother 50: 2602-2607, 2006.

23. DeForge LE, Billeci KL and Kramer SM: Effect of IFN-gamma on the killing of $S$. aureus in human whole blood. Assessment of bacterial viability by CFU determination and by a new method using alamarBlue. J Immunol Methods 245: 79-89, 2000.

24. Tenover FC, Swenson JM, O'Hara CM and Stocker SA: Ability of commercial and reference antimicrobial susceptibility testing methods to detect vancomycin resistance in enterococci. J Clin Microbiol 33: 1524-1527, 1995.

25. Yajko DM, Madej JJ, Lancaster MV, Sanders CA, Cawthon VL, Gee B, Babst A and Hadley WK: Colorimetric method for determining MICs of antimicrobial agents for Mycobacterium tuberculosis. J Clin Microbiol 33: 2324-2327, 1995.

26. Lehrer RI, Barton A, Daher KA, Harwig SS, Ganz T and Selsted ME: Interaction of human defensins with Escherichia coli. Mechanism of bactericidal activity. J Clin Invest 84: 553-561, 1989. 
27. Lehrer RI, Barton A and Ganz T: Concurrent assessment of inner and outer membrane permeabilization and bacteriolysis in E. coli by multiple-wavelength spectrophotometry. J Immunol Methods 108: 153-158, 1988

28. Ciornei CD, Sigurdardottir T, Schmidtchen A and Bodelsson M: Antimicrobial and chemoattractant activity, lipopolysaccharide neutralization, cytotoxicity, and inhibition by serum of analogs of human cathelicidin LL-37. Antimicrob Agents Chemother 49: 2845-2850, 2005.

29. Ouhara K, Komatsuzawa H, Yamada S, Shiba H, Fujiwara T, Ohara M, Sayama K, Hashimoto K, Kurihara H and Sugai M: Susceptibilities of periodontopathogenic and cariogenic bacteria to antibacterial peptides, $\beta$-defensins and LL37, produced by human epithelial cells. J Antimicrob Chemother 55: 888-896, 2005.

30. Mah TF and O'Toole GA: Mechanisms of biofilm resistance to antimicrobial agents. Trends Microbiol 9: 34-39, 2001.

31. Abe N, Kadowaki T, Okamoto K, Nakayama K, Ohishi M and Yamamoto K: Biochemical and functional properties of lysinespecific cysteine proteinase (Lys-gingipain) as a virulence factor of Porphyromonas gingivalis in periodontal disease. J Biochem (Tokyo) 123: 305-312, 1998.
32. Kadowaki T, Yoneda M, Okamoto K, Maeda K and Yamamoto K: Purification and characterization of a novel arginine-specific cysteine proteinase (argingipain) involved in the pathogenesis of periodontal disease from the culture supernatant of Porphyromonas gingivalis. J Biol Chem 269: 21371-21378, 1994.

33. Pike R, McGraw W, Potempa J and Travis J: Lysine- and arginine-specific proteinases from Porphyromonas gingivalis. Isolation, characterization, and evidence for the existence of complexes with hemagglutinins. J Biol Chem 269: 406-411, 1994.

34. Matsuzaki K: Why and how are peptide-lipid interactions utilized for self-defense? Magainins and tachyplesins as archetypes. Biochim Biophys Acta 1462: 1-10, 1999. 